\title{
FIFTH GÉOTECHNIQUE SYMPOSIUM IN PRINT
}

\author{
Performance of propped and cantilevered rigid walls
}

\section{Discussion}

\section{Professor J. B. Burland, Imperial College of Science and Technology}

I should like to draw attention to a feature of the observed ground movements presented by Tedd et al. which could be misleading. Figs 11(a) and 11(b) in the Paper show the horizontal and vertical movements of the ground surface behind the wall. It is evident that these are very large close to the wall. Reference to Fig. 12 shows that these large movements are concentrated around the temporary shoring which must have undergone significant movement. Thus the observed surface movements in the vicinity of the wall do not reflect any deep-seated effect but merely a local construction detail. Any comparison between theoretical and observed displacement profiles should take this into account.

\section{P. Tedd}

In addition to the substantial movements of the ground behind the wall in the vicinity of the temporary shoring and the need for account to be taken of this in any comparisons between theoretical and observed displacement profiles, discrepancies between the predicted and measured behaviour will have resulted from the effects of wall installation. 'I'he elasto-plastic finite element analyses carried out to provide a class A prediction of behaviour (Potts \& Burland, 1983) assumed that the installation of the wall would have no effect on the stress state in the ground. However, as shown in the Paper significant ground movements were measured during the construction of the wall (Fig. 12) and these were accompanied by reductions in horizontal stress in the ground (Fig. 9). These movements extended to a considerable depth and distance from the wall and were probably associated with the method of wall construction in which the pile boreholes through the London Clay were generally left unsupported for several hours between withdrawal of the casing and pouring of the concrete.

\section{REFERENCE}

Potts, D. M. \& Burland, J. B. (1983). A numerical investigation of the retaining walls of the Bell Common tunnel. TRRL Supplementary Report 783, Transport and Road Research Lahoratory, Crowthorne.

\section{T. R. M. Wakeling, Delft Geotechnics UK ltd}

I should like to comment on the prop loads recorded in the roof beams of Bell Common Tunnel. Fig. 16 of the paper by Tedd et al. showed that the Kork Pak insertion had compressed only $8 \mathrm{~mm}$ out of a total thickness of $75 \mathrm{~mm}$. This suggests that relatively little of the lateral load had been transferred to the roof structure. One interpretation of the observations given in the Paper would be that, by the end of construction, the walls were still behaving largely as cantilevers. Could the Authors indicate the trend in observations subsequent to the date of the Paper?

\section{P. Tedd}

Mr Wakeling's interpretation of the observations that the walls at Bell Common are behaving largely as cantilevers appears to be correct. A further $4 \mathrm{~mm}$ compression of the Kork Pak has occurred to date (March 1985) since that reported in the Paper. Over this period the maximum movement of the top of the wall has increased by about $10 \mathrm{~mm}$ with the results indicating a smaller seasonal variation. The strain observations in the wall from which the bending moments have been derived also indicate that the wall is behaving more as a cantilever now, 2 years after construction, than it was immediately after construction (stage VI in Fig. 15 of the Paper). Measurements inside the tunnel show that heave of the ground has continued steadily but at a decreasing rate.

M. D. Bolton and W. Powrie, Cambridge University Engineering Department

Tedd et al. note that the bending moments estimated from the measured earth pressure distribution are an order of magnitude greater 
than those measured directly. The measurements of earth pressures should not, however, be discounted. Together with the measured prop force, these earth pressures maintain the wall in horizontal and rotational equilibrium, at least within the bounds of experimental error. It is instructive to plot the bending moment diagram which results from the prop force and earth pressures measured at stage VI.

The free-body diagram for the wall above a depth of $16 \mathrm{~m}$ is shown in Fig. 1. The earth pressures are taken from Tedd et al., Fig. 7(b), and the propping force from their Fig. 16(b). The external moment applied at the level of the prop results from the weight of the roof structure $(160 \mathrm{kN} / \mathrm{m})$, the protection slab and the earth fill $(0.7 \mathrm{~m}$ thickness $\times 22 \mathrm{~m}$ span $\times 20$ $\mathrm{kN} / \mathrm{m}^{3}$ unit weight $\times \frac{1}{2}=154 \mathrm{kN} / \mathrm{m}$ ) acting at an eccentricity of $1 \mathrm{~m}$ from the neutral axis of the wall. The shear force and bending moment that are necessary to keep this portion of the wall in horizontal and rotational equilibrium are shown acting on the imaginary cut at a depth of $16 \mathrm{~m}$.

The resulting bending moment diagram is shown in Fig. 2 (sign convention: a positive bending moment causes tension on the excavated side, so that positive curvature is convex towards the excavation). Two points are immediately apparent

(a) there is no reversal of the sign of the bending moment beneath the excavation as predicted by the elastic finite element analyses used by Hubbard et al., Fig. 13

(b) the magnitudes of the bending moments are far in excess of those measured directly (Tedd et al., Fig. 15(b)) and are rather larger than those indicated by Hubbard et

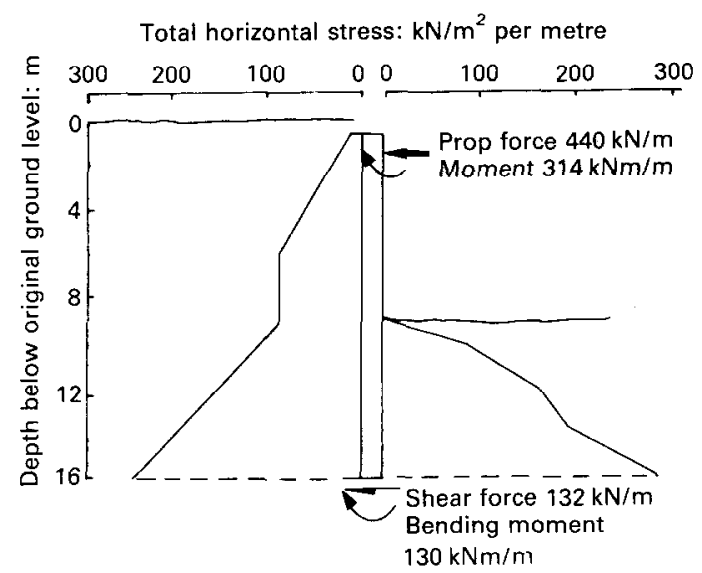

Fig. 1. Free-body diagram for the Bell Common wall (data from Tedd et al., stage VI) al. on the basis of finite element computations.

It is interesting to note that the magnitudes of the negative bending moments predicted by an elasto-plastic finite element analysis (Potts \& Burland, 1983) are apparently much smaller than those predicted by the elastic finite element analysis used by Hubbard et al.

It seems, then, that there is still considerable doubt about the sense and the magnitude of both the actual and the predicted bending moment which occurs in the wall. This is one of the issues of diaphragm wall behaviour which is currently being investigated in a series of model tests in the Cambridge Geotechnical Centrifuge supported by the Transport and Road Research Laboratory.

A model test at a scale of $1: 125$ decreases the time taken for porewater pressure equilit ion by a factor of $125^{2}$, enabling the long $\mathbf{n}$ behaviour of a geotechnical construction tc e observed over a period of hours, rather than years. It is necessary to subject the model to a centrifugal acceleration of $125 \mathrm{~g}$ to ensure that the self-weight stresses at corresponding depths in the model and in the prototype are the same (Schofield, 1980).

Several model diaphragm wall tests have been executed, representing a variety of depths of

Bending moment: $\mathrm{kNm}$ per metre

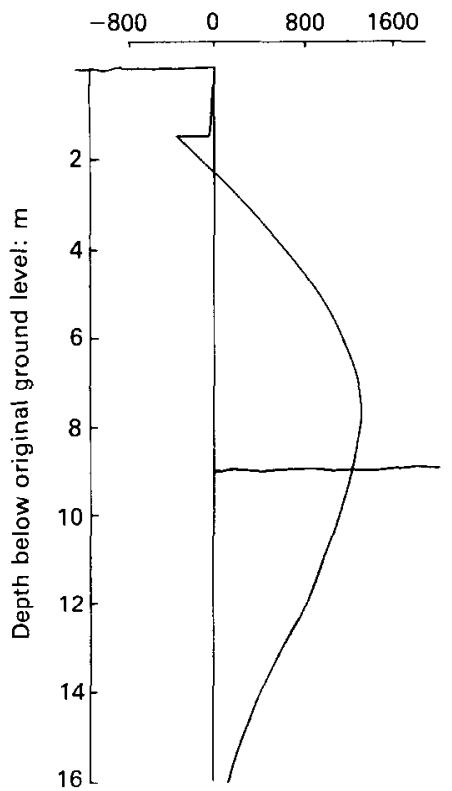

Fig. 2. Bending moment diagram for the Bell Common wall (stage VI) 
embedment and propping conditions: here we present some of the results from a wall whose geometry is similar to the Bell Common wall now under discussion. This is illustrated at prototype (i.e. full) scale in Fig. 3. The model wall retains stiff, overconsolidated Speswhite kaolin and has a full-height groundwater level on its retained side. Kaolin has a saturated unit weight $\gamma$ of around $17.3 \mathrm{kN} / \mathrm{m}^{3}$ and $\phi_{\text {crit }}^{\prime} \approx$ $21.6^{\circ}$ compared with London Clay for which $\gamma=20 \mathrm{kN} / \mathrm{m}^{3}$ and $\phi^{\prime}=20-25^{\circ}$. For all these reasons the model wall is less stable than that at Bell Common. Further, the model wall represents a prototype bending stiffness of $10^{7} \mathrm{kNm}^{2} / \mathrm{m}$, compared with $2.33 \times 10^{6} \mathrm{kNm}^{2} / \mathrm{m}$ at Bcll Common. The model props are also effectively rigid and are placed level with the retained surface.

The bending moments in the model wall were measured directly using a number of fully active strain gauge bridges. The bending moments induced on 'excavation' in front of the wall are shown in Fig. 4. Owing to a shift of the initial zero readings of the gauges attached to this particular wall, increments of bending moment induced on excavation, rather than absolute values, are plotted. The two most striking features of the incremental bending moment diagram of Fig. 4 are

(a) there is no reversal of sign

(b) the magnitudes of the bending moments are of the same order as those obtained from a limit equilibrium stability analysis.

While it is true that this model wall is possibly only on the verge of stability, it is difficult to imagine that the few metres of extra penetration required to impart a high degree of stability would drastically alter the pattern of bending moments induced in the wall. It should, however, be borne in mind that the very high

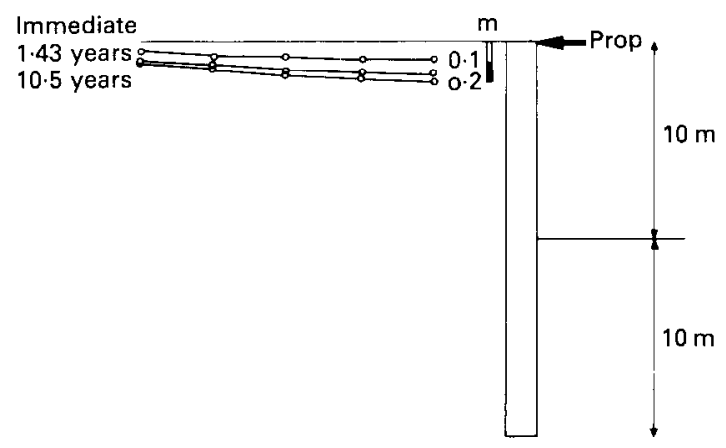

Fig. 3. Centrifuge test DWC10: geometry and post-excavation soil settlements behind the wall stiffness of the model wall is probably partly responsible for the magnitudes of the bending moments.

Figure 3 illustrates the immediate and long-term soil settlements which occurred in the model test. This behaviour is in interesting contrast with the long-term heave predicted by the elasto-plastic finite element analysis of Potts \& Burland (1983).

\section{REFERENCES}

Potts, D. M. \& Burland, J. B. (1983). A numerical investigation of the retaining walls of the Bell Common tunnel. TRRL Supplementary Report 783, Transport and Road Research Laboratory, Crowthorne.

Schofield, A. N. (1980). Cambridge Geotechnical Centrifuge operations. Géotechnique 30, No. 3, 225-268.

\section{P. Tedd}

Dr Bolton and $\mathrm{Mr}$ Powrie have calculated bending moments from the earth pressures and prop forces measured at Bell Common. However, as mentioned in the Paper the bending moment distribution is heavily dependent on the magnitude of the prop force which can only be treated as an approximate estimate. They also refer to the differences in the magnitudes of the bending moments predicted from the elastic and elasto-plastic finite element

Bending moment: $\mathrm{kNm}$ per metre

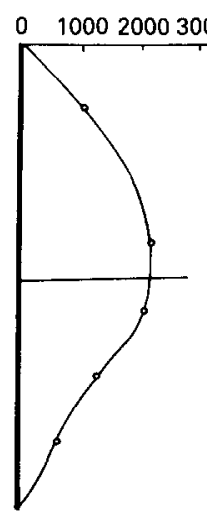

Test DWC10 Change in bending moments induced by 'excavation' in front of wall

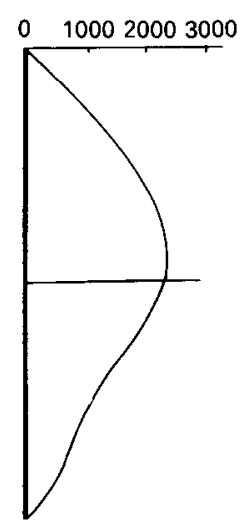

Limit equilibrium analysis FOS $=1 \cdot 0$ $\phi^{\prime}=26^{\circ}$ Full wall friction Full seepage
Fig. 4. Centrifuge test DWC10: bending moments induced by excavation in front of the wall 
analyses and these may be due to the differing assumptions made in these analyses concerning the earth pressures at rest.

Bolton and Powrie have also presented very interesting data concerning measured bending moments and settlements behind a centrifugal model of a propped embedded wall retaining overconsolidated kaolin. However, they do not include any information on the deformations. Since the model wall was reported to be rigidly propped and probably only on the verge of stability the pattern of wall movement would be expected to have differed significantly from that at Bell Common where a compressible prop was installed after some excavation had taken place. In addition the model wall was appreciably stiffer than that at Bell Common. These effects may account for the differences in bending moment measured in the model tests and those determined from the strain gauges installed in the wall at Bell Common. It would be of interest to know whether the increased ground settlements measured behind the model wall in the longer term are a direct result of an increase in inward rotation of the wall about the prop position.

\section{D. Bolton, Cambridge University Engineer- ing Department}

I should like to discuss the issue of the extrapolation of the lateral stress data of Tedd ef al.

In their Fig. 9 Tedd et al. showed a marked drop in total horizontal stress between $0.6 \mathrm{~m}$ and $3 \mathrm{~m}$ from the rear face of the wall, as indicated on spade cells. They also noted that an allowance was made for overreading due to push insertion, of magnitude $0 \cdot 3 c_{u}$ in the Claygate Beds and $0 \cdot 5 c_{\mathrm{u}}$ in the London Clay.

Although a cross-check on the validity of this procedure was possible for remote cells using self-boring pressuremeter data on the undisturbed soils before construction, no such check was possible on the cells located $0.6 \mathrm{~m}$ from the wall, which were inserted only after pile construction. The assumed magnitude of the overread on these cells lay between $24 \mathrm{kN} / \mathrm{m}^{2}$ at $6 \mathrm{~m}$ depth and $64 \mathrm{kN} / \mathrm{m}^{2}$ at $12 \mathrm{~m}$.

The typical drop in stress between $0.6 \mathrm{~m}$ and $3 \mathrm{~m}$ from the wall, as indicated by these corrected readings, is about $20 \mathrm{kN} / \mathrm{m}^{2}$ at $6 \mathrm{~m}$ depth and about $70 \mathrm{kN} / \mathrm{m}^{2}$ at $9 \mathrm{~m}$ and $12 \mathrm{~m}$. Care needs to be taken in the extrapolation of these results. First linear distributions of stress with depth between these points, and in extrapolation to the wall base, are assumed, taking zero at ground level. The equilibrium of a rectangular block of soil $20 \mathrm{~m}$ high and $2.4 \mathrm{~m}$ wide can then be assessed. The unbalanced lateral force on the inside and outside faces of the block can be shown to be $965 \mathrm{kN} / \mathrm{m}^{2}$. If no side support for a block of unit width is taken, which is tantamount to an assertion that the data of Fig. 9 in the Paper can be applied everywhere along a line that is parallel to the relatively very long wall, then a base shear stress of $965 / 2 \cdot 4=402 \mathrm{kN} / \mathrm{m}^{2}$ must be invoked for equilibrium. Such a value would exceed by a factor of 2 the shear strength available according to the Authors' Fig. 1.

There are three potential explanations which might be reasonable

(a) the stresses of Fig. 9 cannot be extrapolated vertically over the whole wall

(b) the stresses of Fig. 9 cannot be extrapolated horizontally over the whole wall

(c) the routine $0 \cdot 5 c_{\mathrm{u}}$ adjustment to the reading of the spade cells is unjustified.

It would be valuable to have the Authors' opinion on whether the data of bending moments would support the hypothesis that the spade cell nearest the wall was overcorrected and, if not, which of alternatives (a) or (b) is to be preferred. The extent and pattern of soil strain below $6 \mathrm{~m}$, according to Fig. 12 of the Paper, was dominated by the process of pile construction. Might it not be that in a construction remote from failure the lateral stresses on a horizontal line parallel to the back face of the wall, and only $0.6 \mathrm{~m}$ from it, could display significant variations with a wavelength of one pile diameter?

\section{P. Tedd}

Dr Bolton has made an interesting observation and all his possible explanations could have contributed to the very large unbalanced lateral force that he has calculated on the block of soil $20 \mathrm{~m}$ high between $0.6 \mathrm{~m}$ and $3 \mathrm{~m}$ from the back of the wall.

(a) The extrapolation of the data vertically below the deepest stress observation makes a major contribution to the unbalanced force. If, however, the equilibrium of the block of soil between $0.6 \mathrm{~m}$ and $3.0 \mathrm{~m}$ from the wall down to a depth of $12 \mathrm{~m}$ is considered, then the unbalanced lateral force is only $405 \mathrm{kN}$ and the base shear resistance is $169 \mathrm{kN} / \mathrm{m}^{2}$. This value is not significantly greater than the shear strength of the London Clay at that depth. Clearly errors arising from extrapolating a constant reduction in stress of $70 \mathrm{kN} / \mathrm{m}^{2}$ across the 
block of soil from a depth of $12 \mathrm{~m}$ down to $20 \mathrm{~m}$ could explain the unreasonably large unbalanced force on the block of soil $20 \mathrm{~m}$ high. Indeed the observations indicate that the reduction in stress across the block at $9 \mathrm{~m}$ depth was greater than that at $12 \mathrm{~m}$ depth, thus suggesting that the lateral stress reduction across the block decreases with depth.

(b) Without several measurements at the same depth and at the same distance from the back of the wall it is impossible to know the variation in the lateral stress on a horizontal line parallel to the back of the wall. From the method of constructing the wall some variation close to the wall might be expected. Measurements with the spade cells installed at the same depth in the undisturbed ground indicated a horizontal variation in lateral stress of no more than $\pm 25 \mathrm{kN} / \mathrm{m}^{2}$.

(c) From the experience of Tedd \& Charles (1983) and others it is evident that spade cells that are installed in stiff clay over read by a small but significant amount and therefore some corrections to the observations are necessary. When a correction of $0 \cdot 5 c_{u}$ was applied to the spade cell measurements at Bell Common good agreement was obtained with the self-boring pressuremeter measurements. The magnitude of the overreading at Bell Common could be considered to be based on the comparison with the lateral earth pressures that were measured with the self-boring pressuremeter in the undisturbed ground before construction and the relationship between $c_{\mathrm{u}}$ and overreading need not be invoked. Clearly the accuracy of the overreading determined in this way depends on a number of variables including the validity of the self-boring pressuremeter measurements, any natural variations in lateral stress in a horizontal plane in the ground and whether the same overreading would occur when the spade cells were installed in disturbed ground such as that close to the wall at Bell Common.

Any increase in earth pressure on the upper part of the back of the wall resulting from a smaller correction for overreading of the spade cells will reduce the magnitude of the positive bending moments, and therefore bring them closer to those determined from the strain gauges. However, even if the spade cells nearest the wall were not corrected for overreading, the resulting increase in lateral pressure on the back of the wall above the excavation level would reduce the magnitude of the positive bending moments by less than 5\%. It should also be pointed out that the earth pressures measured $0.6 \mathrm{~m}$ from the back of the wall are not necessarily those acting on the wall. As stated in the Paper it was the high estimated prop force that had a dominating effect on the calculated bending moments. It is only by substantially reducing the prop force that these bending moments can be brought close to those determined from the strain gauges in the wall.

\section{REFERENCE}

Tedd, P. \& Charles, J. A. (1983). Evaluation of push-in pressure cell results in stiff clay. Proc. Int. Symp. Soil and Rock Investigation by In-situ Testing, Paris 2, 16-21.

\section{Garrett}

The ground investigations for the final design of the M25 and M26 motorways in Kent, which include the Dunton Green retaining walls, began approximately 10 years ago. Very little information was found concerning the engineering properties and behaviour of Gault Clay in general, let alone how it affects the design of earth retaining structures. This scarcity of data was particularly surprising when compared with the amount of information available for another similar overconsolidated clay, London Clay. The reasons for this are partly explained by McRae \& Burnham (1973) of Wye Agricultural College who adequately expressed the state of affairs in the following manner.

'The Gault Clay stratum has been avoided by Man who has not built any villages directly on it. This corridor of sparce settlement is attractive to the road planner although the actual Road Engineer may encounter considerable problems.

Relatively few buildings are to be found to be built directly onto the Gault Clay because of its swelling and shrinking properties related to moisture content changes which disrupt the foundations of buildings.'

In addition to this lack of knowledge concerning the properties and behaviour of Gault Clay, there were significant doubts at that time concerning appropriate methods for the design of some types of retaining walls in heavily overconsolidated clays. The Dunton Green retaining walls pre-date the other two walls reported to this symposium, most of the design work having been carried out during 
1976-77 at which time of the design the existing Code of Practice for Earth Retaining Structures, CP2, was approximately 25 years old. The use of the design method in that document with effective stress parameters for cantilever retaining walls in clays typically resulted in either such large penetrations that the wall was uneconomic and could not be built or inadequate factors of safety could be obtained whatever the penetration. Such findings did not accord with experienced use of such walls where a ratio of penetration to exposed height of $2: 1$ had generally been found to be adequate both with respect to safety and to movements of the wall and the affected ground.

Since the time of the design of the Dunton Green retaining wall there have been some significant advances, particularly the preparation and publication of the CIRIA report (Construction Industry Research and Information Association, 1984) on this subject. However, it would be a mistake to interpret the publication of such documents as meaning that no further advances in our knowledge and understanding of this subject are necessary. The results of the associated CIRIA retaining wall design competition indicated that for a particular case history $13.1 \mathrm{~m}$ penetration was required for a $4 \mathrm{~m}$ exposed height (the range of solutions submitted being from $4.5 \mathrm{~m}$ to $13.3 \mathrm{~m}$ penetration) and this was for stated parameters, water-tables etc. The parametric studies carried out for the Dunton Green wall indicate the large effect that the choice can have on the resulting wall design. The value-for-money aspect is demonstrated by the type of wall used at Dunton Green whose cost was estimated to be only approximately $20 \%$ of some alternative designs put forward on the basis of other interpretations of the geotechnical parameters, factors of safety and limiting ground strains such as earth pressures at rest, $K_{0}$, plus zero ground strain.

A major feature of the design approach used at Dunton Green was the use of instrumentation during the construction and life of the retaining wall. The most recent wall deformation, ground movement and water-table information has confirmed that the wall still is behaving approximately as designed and predicted, but it must be borne in mind that its age to date, 5 years, is still relatively short when compared with a design life of 120 years. If such instrumentation is not installed, how do we know how economic our designs are or how safe they are throughout their life, including the construction phase? Too often the answer to the latter question is that we do not know until irreversible failure has occurred, which also damages the credibility of the profession.

In the preface to this symposium the authors were criticized for their lack of attention to water-table and/or pore pressure information. There are many reasons for such omissions, including limitations of the length of the Paper, but a major factor often is the question of whether instrumentation is really necessary combined with its financing during construction and particularly during the life of the structure. It is suggested that as individuals and corporately as the British Geotechnical Society more effort must be put into this work, the observational/feedback approach. In this connection it would be advantageous for papers in Géotechnique to include in future more reference to real structures and their performance including the assessment of actual factors of safety, the operative geotechnical parameters and the value-for-money of the chosen designs.

\section{REFERENCES}

Construction Industry Research and Information Association (1984). Design of retaining walls embedded in stiff clays. Report 104, CIRIA, London.

McRae, S. \& Burnham, C. P. (1973). The rural landscape of Kent. Ashford: Wye College (University of London).

\section{K. R. Gabriel, A. F. Howland Associates}

In his Paper Mr Garrett indicated that the Dunton Green retaining wall was constructed in Gault Clay, the uppermost horizons of which had suffered solifluction and cryoturbation processes to depths of $3-4 \mathrm{~m}$, while the wcathercd zone was reported to reach depths of 5-11 m. No mention was made, however, of the presence or absence of valley bulging features which can lead to the development of major shear planes with strengths reduced to residual values (Hollingworth, Taylor \& Kellaway, 1944; Horswill \& Horton, 1976).

It is understood that for the design residual shear strength parameters $\left(c^{\prime}=0 \mathrm{kN} / \mathrm{m}^{2}, \phi^{\prime}=\right.$ $\left.14^{\circ}\right)$ were applied to the soliffucted and cryoturbated deposits, whereas peak strength parameters $\left(c^{\prime}=13 \mathrm{kN} / \mathrm{m}^{2}, \quad \phi^{\prime}=24 \cdot 5^{\circ}\right)$ were used for the weathered and unweathered clay. As the design of retaining walls is very sensitive to small changes in $c^{\prime}$, and to a lesser extent $\phi^{\prime}$, the correct identification of the presence of residual shear strengths is most important.

The $1-2 \mathrm{~km}$ wide Gault Clay outcrop in the bottom of the Darent valley forms an apparently suitable setting for the development of valley bulging features. Since the major 
discrete shear planes associated with valley bulging could develop within the weathered and unweathered units of the clay, for which peak shear strength parameters rather than residual parameters were used, their presence could have significantly influenced the design of the retaining walls. Accordingly could Mr Garrett comment on any evidence found for the presence or absence of valley bulging features at Dunton Green?

\section{REFERENCES}

Hollingworth, S. E., Taylor, J. H. \& Kellaway, G. A. (1944). Large-scale superficial structures in the Northampton ironstone field. Q. J. Geol. Soc. Lond. 100, 1-44.

Horswill, P. \& Horton, A. (1976). Cambering and valley bulging in the Gwash valley at Empingham, Rutland. Phil. Trans. R. Soc. 283A, 427-462.

\section{Garrett and S. J. Barnes}

Such valley bulging effects have been observed in certain locations and strata in Kent and it is thought to be probable that the Gault Clay outcrop has been similarly affected particularly at such a location as Dunton Green which is effectively at the intersection of two initiating features, namely

(a) the Gault Clay vale running approximately east-west

(b) the River Darent valley running approximately north-south.

Although borehole samples and exposures in trial pits were examined for such valley bulging features, none were found.

The detection of such valley bulging effects are expedited and facilitated by the presence of physical, colour or other marker bands. However, owing to the superficial homogeneity of the Gault Clay it is thought that it would be difficult to detect the relatively deep valley bulging effects from the results of ground investigations that are designed to facilitate the assessment of the engineering behaviour of relatively near-surface excavations and constructions. Hence to detect such features conclusively a special investigation extending to much greater depth and at different locations as well as involving techniques such as fossil and/or microfossil examination would probably be required. For such an investigation a 'grid' layout would be more appropriate than the 'linear' layout which normally pertains in ground investigations for highways.

Mr Gabriel also infers that, as such valley bulging features would be accompanied by shear zones, the design of structures such as the Dunton Green retaining wall should be based on residual parameters which probably pertain along such shear surfaces. As indicated above, the scale of the valley bulging effects is probably markedly larger than the scale of the retaining wall and its associated excavation. The performance of such structures is mainly determined by the bulk properties of the ground in the zone of influence and not by those of specific surfaces in or outside the zone of influence. Essentially residual parameters are only appropriate if they represent the bulk properties of the material in the direction of ground strain throughout the zone of influence, a situation which rarely occurs with a retaining wall of the cantilever bored pile type. If the position and properties of such layers are accurately known they can be modelled in the analysis, otherwise appropriately conservative bulk properties can be used as at Dunton Green. Suffice it here to say that this latter approach and the magnitude of the geotechnical parameters used for the Gault Clay have been endorsed by the successful performance of these retaining walls approximately as predicted. In contrast, if residual parameters did accurately represent the behaviour of the Gault Clay at Dunton Green it would not have been possible to design or construct successful cantilever bored pile retaining walls and some other, more expensive, type of wall construction would have been necessary.

\section{R. J. Jardine, Imperial College of Science and Technology}

The earth pressures at Dunton Green were measured using a cylindrical pressure meter. This device is most often employed to find the average horizontal stresses at sites where the radial stresses, at any level, are assumed to be equal in all directions. The construction sequence at Dunton Green would be expected to disrupt this axial symmetry. The stresses in the horizontal axis perpendicular to the road might be expected to tend towards passive conditions in front of the wall, with $\sigma_{\mathrm{H}}{ }^{\prime} \rightarrow \sigma_{1}{ }^{\prime}$, and active conditions in the retained soil, with $\sigma_{\mathrm{H}}{ }^{\prime} \rightarrow \sigma_{3}{ }^{\prime}$. Parallel to the axis of the road, however, the horizontal stresses would be nearer to $\sigma_{2}{ }^{\prime}$ and would lie between $\sigma_{1}{ }^{\prime}$ and $\sigma_{3}{ }^{\prime}$.

How did Clarke and Wroth deal with such stress inhomogeneities in their interpretations of the pressuremeter data, and might not the influence of $\sigma_{2}{ }^{\prime}$ have partly caused the apparent overreading and underreading of the earth pressures? 


\section{Professor C. P. Wroth}

The measurement of the expansion of the membrane of the self-boring pressuremeter is made by three separate feelers which are symmetrically placed around the circular section of the pressuremeter and act on the central plane of the membrane. Each feeler gives an electrical signal, so that the movement of each of the threc points on the membrane is recorded. In ground which has the same in situ horizontal stress in all directions, it is expected that the membrane will expand uniformly and remain circular in section, with the lift-off pressure given by each feeler being the same.

At Dunton Green, where the process of excavation will disrupt the axial symmetry of the horizontal stress, the membrane can be expected to expand non-uniformly (presumably so that it takes up an elliptical shape in section). The lift-off of the three feelers will not occur simultaneously, and they will not indicate the same in situ horizontal stress.

By arranging for one feeler arm to act in a plane that is perpendicular to the retaining wall, the lift-off pressure from that arm can be used alone to estimate the total horizontal stress acting in the ground perpendicular to the wall. This lechnique was adopted at Dunton Green.

$\mathrm{Mr}$ Dalton of Cambridge Insitu has reported results of tests in the Gault Clay in which consistent and marked anisotropy of horizontal stresses has been observed by using this method.

\section{J. C. P. Dalton, Cambridge Insitu}

Some tests have been carried out in the Gault Clay at Eversden, near Cambridge, where substantial degrees of anisotropy were revealed by large differences, up to $2: 1$ ratio, in the lift-off pressures between the three strain arms of an expansion pressuremeter (Dalton \& Hawkins, 1982). This observation of considerable anisotropy in stiff clay has also been made subsequently by Professor Jamiolkowski and Dr Ghionna at La Spezia in Italy (Ghionna, Jamiolkowski \& Lancellota, 1982). Using a machine identical with that used at Dunton Green they went, in 3-4 m of water, first through a soft clay layer showing complete isotropy and then immediately into a stiff clay layer showing a considerable degree of anisotropy.

There has been some discussion subsequently both about whether the instruments were being pushed on a straight path and about whether there was not an artefact on the surface of the instrument giving rise to the effect observed.
However, in the tests at Little Eversden two completely different self-boring instruments were used. The second was a load cell pressuremeter in which the outside curved surface of the cylindrical instrument is designed purcly to mcasure the in situ stress continuously. A rotation of this instrument in the ground confirmed a horizontal anisotropy of the in situ stress that was very similar to that shown by the expansion pressuremeter tests at the same site.

\section{REFERENCES}

Dalton, J. C. P. \& Hawkins, P. G. (1982). Fields of stress; some measurements of the in-situ stress in a meadow in Cambridgeshire. Ground Engng 15, No. 4, 15-22.

Ghionna, V. N., Jamiolkowski, M. \& Lancellota, R. (1982). Characteristics of saturated clays as obtained from SBP tests. Proc. Symp. Pressuremeter and its Marine Applications, Paris, pp. $165-185$.

\section{A. Raison, Ove Arup \& Partners}

The new British Library is currently under construction on the north side of Euston Road adjacent to St Pancras station (Fig. 5). Unfortunately progress on site was not sufficiently advanced for us to present a paper in the Symposium in Print. However, we now have some preliminary results of ground movements which we wish to present. These results have been processed and stored by computer which has enabled us to develop a number of different ways of plotting and displaying data. Examples of these are included here.

Preliminary substructure works were carried out during 1982 and 1983 and have been described in detail elsewhere (1984). These included the installation of secant piles to form the basement retaining walls, excavation up to $5 \mathrm{~m}$ below street level to remove old foundations and the construction of large diameter underreamed bored piles. Of particular interest is that the pile cut-off level is at a level $24 \mathrm{~m}$ below street level which necessitated leaving an empty bore above each pile lined with flexible Armco casing.

Ground movements were anticipated as a result of the limited excavation and the horizontal stress relief caused by the bored piling. At this stage of construction the retaining walls were not propped and were acting as cantilevered walls. To measure these movements a considerable quantity of ground instrumentation has been installed within and around the site. In addition 20 secant piles were installed with inclinometer access tubes which 


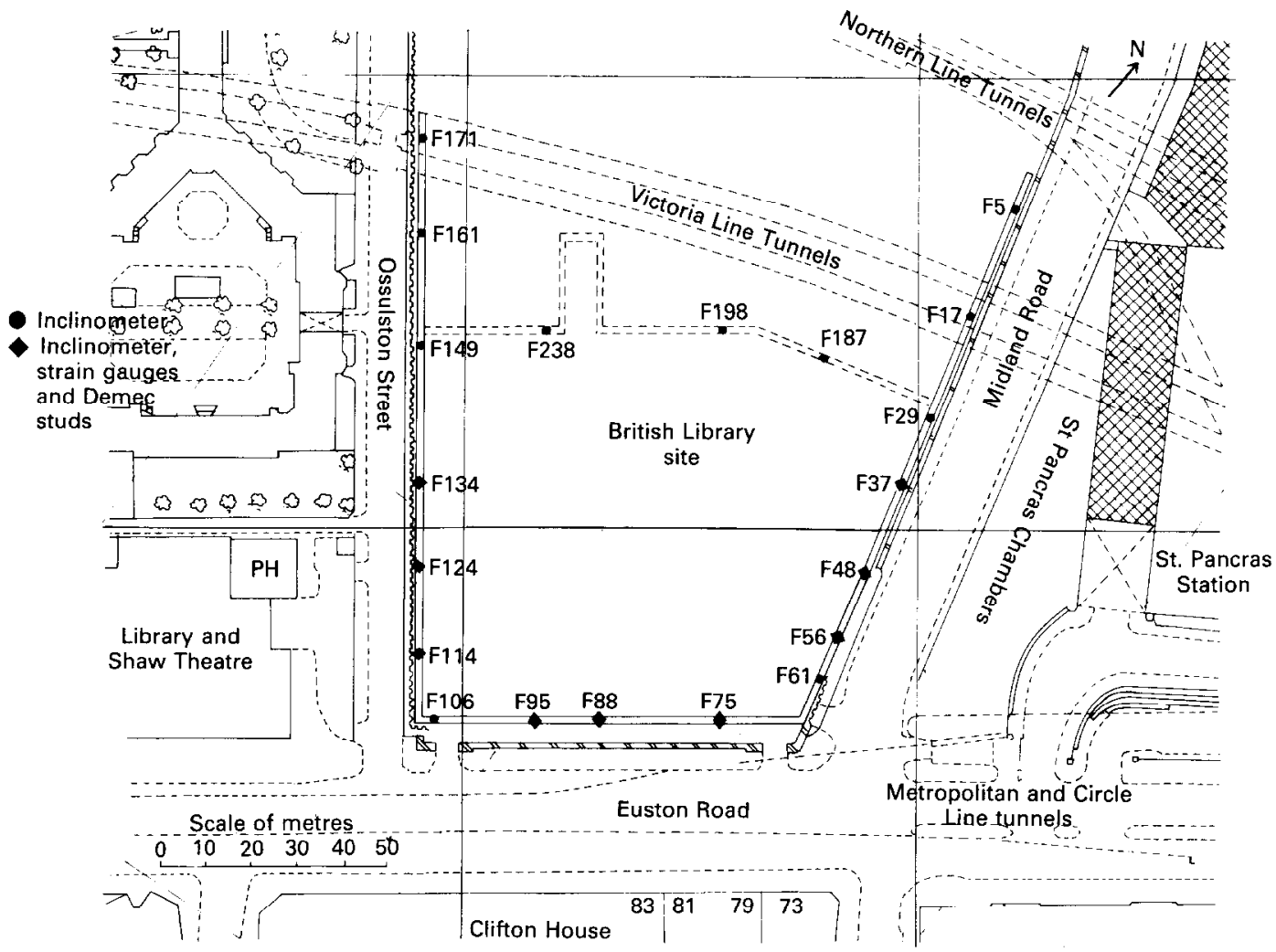

Fig. 5. Secant pile instrumentation

have been monitored on a regular basis since installation (Fig. 5).

An attempt was made to measure ground movements in inclinometers close to the line of the retaining walls during installation of the secant piling. However, negligible movement was recorded in contrast with the large movements recorded during piling for the Bell Common tunnel (Tedd, Chard, Charles \& Symons, 1984). This difference may be attributable to the different piling technique adopted. At the British Library the secant pile bores were cased throughout their depth, casing only being withdrawn during concreting.

The movements measured in the secant pile inclinometers are shown in Fig. 6. This plot shows an inward movement of the top of each wall between $10 \mathrm{~mm}$ and $20 \mathrm{~mm}$ at the mid-point. Although monitoring of these instruments began as soon as possible after installation, some major excavation works were carried out towards the north of the site before commissioning. Ground movements shown may therefore not include some early movement.
Figure 7 shows a comparison between measured wall movements and those predicted by finite element computer analyses using the OAP London Clay model described by Simpson, O'Riordan \& Croft (1979). This plot shows the movements predicted at the top of the secant piles $(+17$ to $+18 \mathrm{~m}$ OD in July 1984) between $10 \mathrm{~mm}$ and $20 \mathrm{~mm}$ and shows a slight but conservative overestimation.

A north-south section is shown in Fig. 8 and includes inclinometer and extensometer movements combined. Up to $30 \mathrm{~mm}$ of heave has been recorded in the central area overlying the London Transport Victoria Line tunnels. Surveys in the tunnels confirm that these have heaved about $4 \mathrm{~mm}$. In the south area stress relief due to the piling has resulted in up to $10 \mathrm{~mm}$ of settlement.

In examining the results presented here it should be borne in mind that at the early stage of construction both the predicted and the measured movements are small and therefore subject to a high proportion of error. This has been particularly so for measured movements 


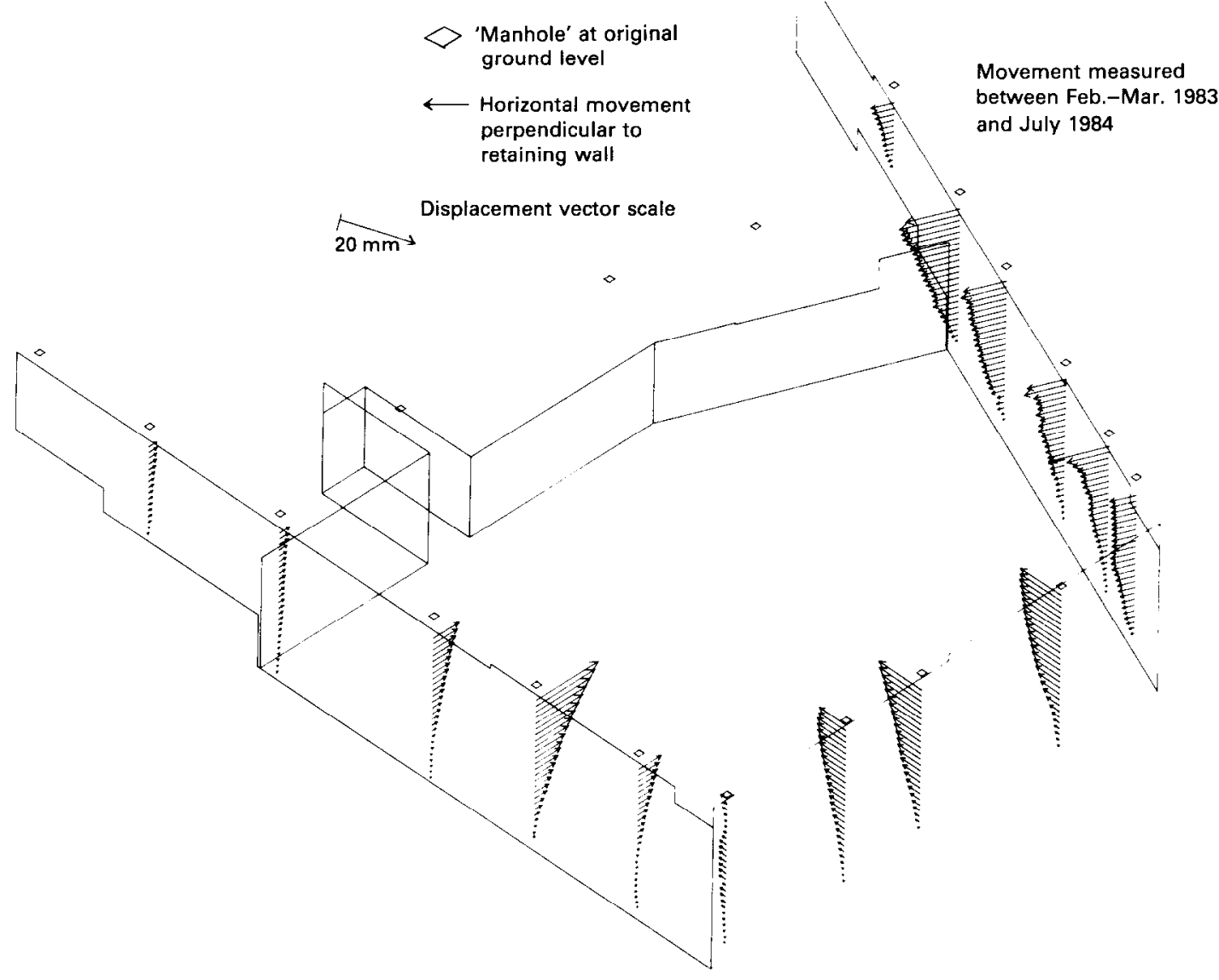

Fig. 6. Secant pile wall movements

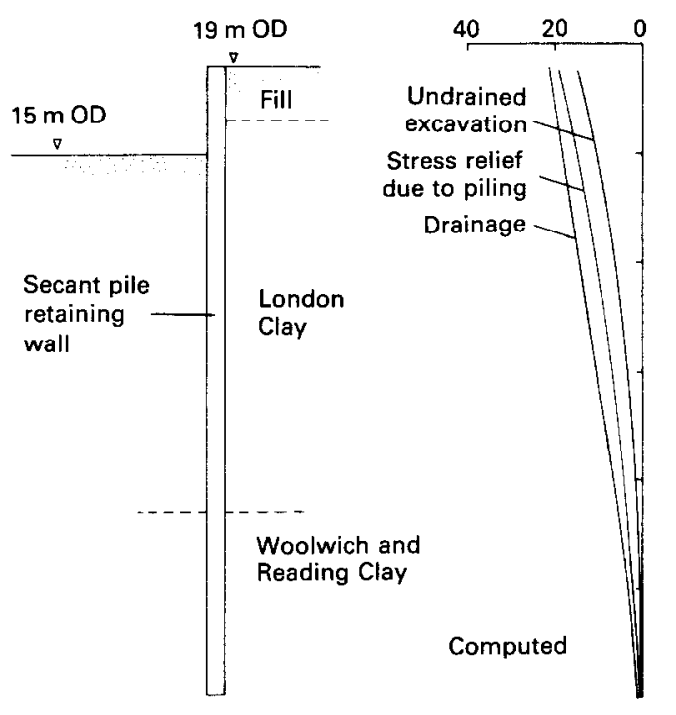

Wall movement: $\mathrm{mm}$

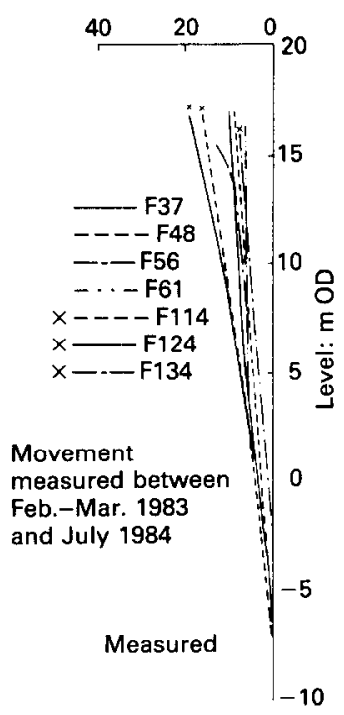

Fig. 7. Comparison between measured wall movements and computed movements 


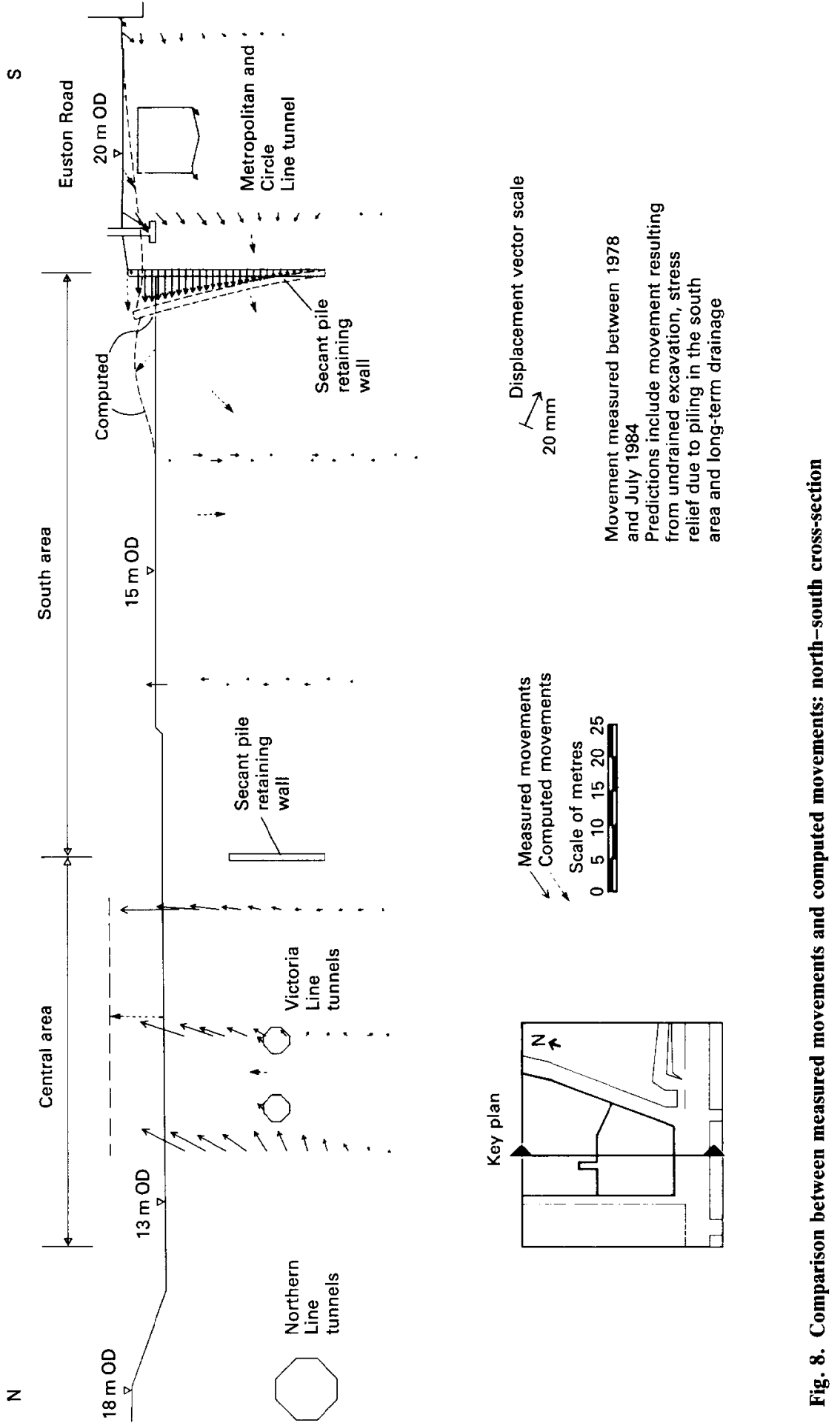




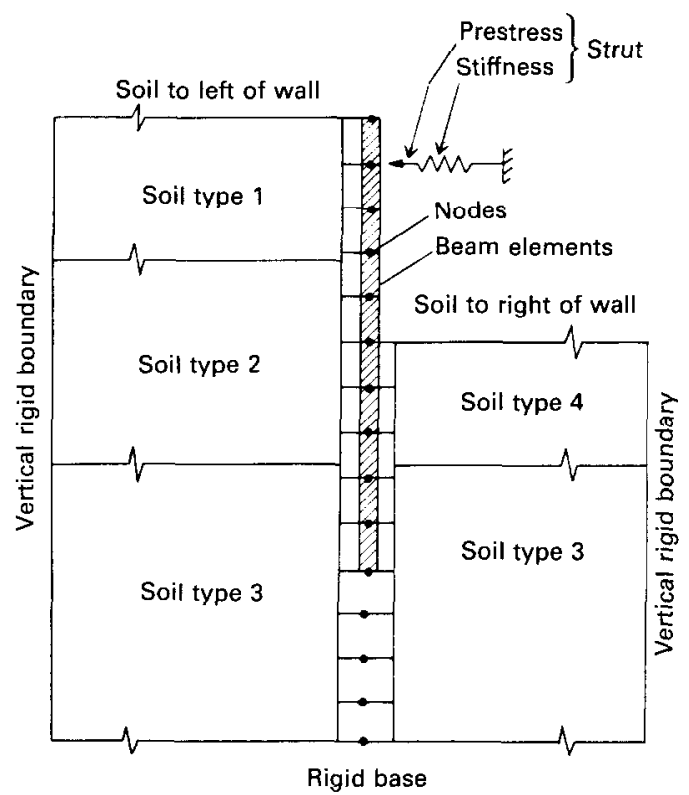

Fig. 9. Numerical representation of the soil-wall problem

where the accuracy and repeatability of the ground instrumentation is large in comparison with the movements.

This note has of necessity been brief and it has not been possible to comment further on the subject of accuracy of the measurements. However, it is hoped that this can be included in a fuller presentation of ground movements associated with the British Library basement excavations to be made at some future date.

\section{REFERENCES}

Ground Engineering (1984). Deep foundations for the British Library. Ground Engng 17, No. 3, 20-26.

Simpson, B., O'Riordan, N. J. \& Croft, D. D. (1979). A computer model for the analysis of ground movements in London Clay. Geotechnique 29, No. 2, 149-175.

Tedd, P., Chard, B. M., Charles, J. A. \& Symons, I. F. (1984). Behaviour of a propped embedded retaining wall in stiff clay at Bell Common Tunnel. Géotechnique 34, No. 4, 513-532.

\section{J. W. Pappin, Ove Arup \& Partners}

Most of the Papers in the symposium refer to the finite element method of analysis being used to predict the behaviour of the retaining walls. The only exception to this is Wood and Perrin who use the program LAWWALL. Ove Arup \& Partners have been using a LAWWALL-type program for several years as an aid to the design of flexible retaining walls. The program, while not being as general as the finite element method, has a significant advantage over the finite element method in that it is much cheaper to use and is sufficiently accurate for most design problems. It is particularly suitable for parametric studies.

The program models the soil-wall interaction problem as shown in Fig. 9. The soil to each side of the wall is represented by an elastic solid, the flexibility of which is generated either by way of the integrals of the Mindlin equations (Vaziri, Simpson, Pappin \& Simpson, 1982) or by interpolation and sealing of flexibility matrices calculated for a simplified soil profile using finite element methods. A semiempirical formulation has been developed to allow for variations in the soil stiffness with depth. The wall stiffness is represented by a series of elastic beam elements. In addition the earth pressures are limited to be within active and passive limits. Arching is permitted by considering the soil forces acting on the wall compared with the forces consistent with possible failure surfaces within the soil. Other features that can be accommodated by the program include struts, anchors and the effects of surcharges.

Full details of the program including various validation procedures are given in Pappin, Simpson, Felton \& Raison (1985).

\section{REFERENCES}

Pappin, J. W., Simpson, B., Felton, P. J. \& Raison, C. (1985). Numerical analysis of flexible retaining walls. Proc. NUMETA '85 Conf., Swansea, Jan., pp. 789-802.

Vaziri, H., Simpson, B., Pappin, J. W. \& Simpson, L. (1982). Integrated forms of Mindlin's equations. Géotechnique 32, No. 3, 275-278.

\section{B. Simpson, Ove Arup \& Partners}

I would like to invite Wood and Perrin to comment further on their choice and use of Young's modulus for the London Clay. They state that the undrained Young's modulus was derived by multiplying the measured undrained shear strengths by a factor of 200 . On the basis of their Fig. 3 this would give a Young's modulus of about $40 \mathrm{MN} / \mathrm{m}^{2}$ at a depth of $20 \mathrm{~m}$, for example. Values derived in this way are considerably less than those which have been found by back analysis by previous researchers. For example, Cole \& Burland (1972) showed a value of about $120 \mathrm{MN} / \mathrm{m}^{2}$ at a depth of $20 \mathrm{~m}$. Similar values were reported from back analyses by St John (1975) and Burland, Simpson \& St John (1979).

The Authors have used their values of 


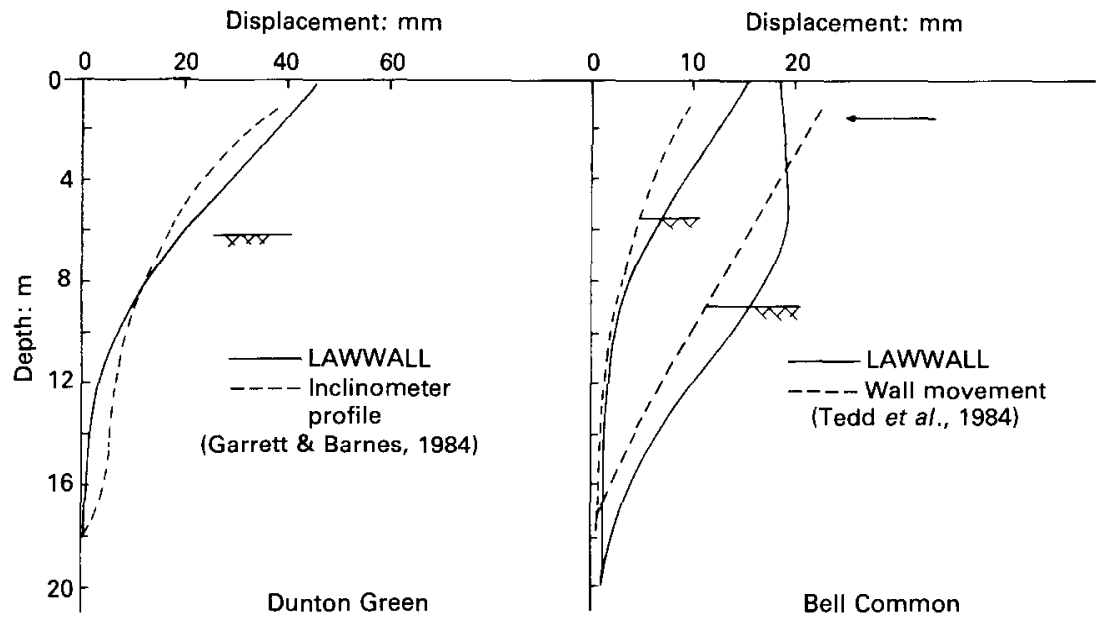

Fig. 10.

Young's modulus together with the LAWWALL program to predict wall movements at their site. It appears that they correctly predicted the small measured movements of up to about $30 \mathrm{~mm}$. They state that the program used a Winkler spring analogy in which the soil is represented as a series of uncoupled springs. It would be helpful to know how the spring stiffnesses are calculated from the assumed profile of Young's modulus. Do the Authors consider that their derivation of spring stiffnesses is valid and that the Young's moduli adopted represent the bulk pseudo-elastic behaviour of the London Clay?

\section{REFERENCES}

Burland, J. B., Simpson, B. \& St John, II. D. (1979). Movements around excavations in London Clay. In Design parameters in geotechnical engineering, Proc. 7th Eur. Conf. Soil Mech., Brighton 1, 13-30.

Cole, K. W. \& Burland, J. B. (1972). Observations of retaining wall movements associated with a large excavation. Proc. 5th Eur. Conf. Soil Mech. Fdn Engng, Madrid 1, 445-453.

St John, H. D. (1975). Field and theoretical studies of the behaviour of ground around deep excavations in London clay. PhD thesis, University of Cambridge.

\section{A. Wood and A. J. Perrin}

Dr Pappin has commented on our use of LAWWALL whereas the other Authors in the symposium have used analyses based on the finite element method. LAWWALL, which was written by Wood in 1977 and is available on the service of the major engineering computer bureaux, was developed to provide a realistic assessment of wall behaviour within the economic constraints associated with everyday design work. The program has been calibrated by the Highway Engineering Computer Branch of the Department of Transport. To illustrate further the use of the program both the Bell Common and Dunton Green walls considered in the symposium have been analysed and the results are presented in Fig. 10, where tolerable agreement with the observed movements is demonstrated.

Dr Simpson has questioned the validity of the adopted value of the undrained Young's modulus $E$ used in the design of the diaphragm wall. The ratio $E / c_{\mathrm{u}}$ used in the design calculations varied somewhat between 200 and 300 , giving rise to an assumed value of Young's modulus of about $60 \mathrm{MN} / \mathrm{m}^{2}$ at a depth of $20 \mathrm{~m}$, which is in excess of the $40 \mathrm{MN} / \mathrm{m}^{2}$ mentioned by $\mathrm{Dr}$ Simpson but is still considerably less than the values obtained from the back analysis, using linear elastic, finite element methods, of similar walls in London. An example of the very wide spread of Young's moduli obtained from back analyses is quoted by Simpson, O'Riordan \& Croft (1979). In view of this and other imponderables, and a desire to investigate the 'worst' case, the conservative value of Young's modulus was used. It is those predictions which have been presented in the Paper; a back analysis of the wall movements will undoubtedly lead to different values dependent on the method of analysis adopted and the additional assumptions made with respect to the other. parameters. However, it is of interest to note 
that in the type of analysis performed within LAWWALL where due consideration is taken of the active and passive earth pressure limits the deformations are not necessarily critically governed by the Young's modulus of the soil. For the multipropped diaphragm wall this is amply demonstrated in Fig. 11. A threefold increase in soil stiffness has a small influence on the computed deformations whereas changes of the same order in stiffness of the props has a much more dramatic effect. Such an occurrence is perhaps fortunate as the design of the propping system lies within the control of the engineer, whereas the determination of the soil stiffness is more problematic.

In the uncoupled spring model the spring stiffnesses are computed using the integrated form of Mindlin's equations, as in the elastic continuum model, but with all the off-diagonal terms in the flexibility matrix set to zero. Hence, the soil model is 'stiffer' than that derived from the coupled elastic continuum. The validity of such an approach is, perhaps, in itself difficult to justify vis-à-vis the continuum model. However, when the development of the active and passive limiting conditions is also considered then the continuum model would also become partially uncoupled and the results generated by the two analyses may not be dissimilar. In Fig. 10 the LAWWALL results for the Bell Common Wall, based on the variation in soil modulus shown in Fig. 10 of the Paper by Hubbard et al., show reasonable agreement with the field measurements as do those for the Dunton Green wall, based on the soil moduli given in Fig. 13(a) of the Paper by Clarke and Wroth.

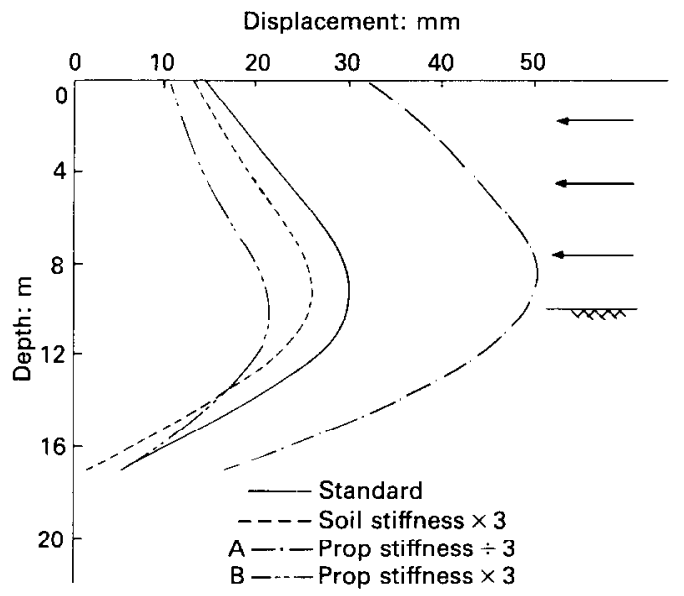

Fig. 11 .
The representation of the bulk behaviour of any soil is difficult but in the complex stress regime associated with flexible retaining walls and excavations yet more so. As to whether or not the Young's moduli adopted represent the bulk pseudo-elastic behaviour of the London Clay it is impossible to say. However, the importance of the chosen values for Young's moduli of the soil, within the context of a computation that also takes into account wall and prop stiffness and the shear strength of the soil, is much diminished when compared with that for a linear elastic model.

The Authors would like to take this opportunity to correct the strain measurements shown in Fig. 11 of the Paper, where the profile obtained from the deflexion of the inclinometer i7 should be ignored. Further work is now in progress on the correlation between strain gauge readings and those deduced from the deflexion profiles, and the corrected results are shown in Fig. 12.

\section{REFERENCE}

Simpson, B., O'Riordan, N. J. \& Croft, D. D. (1979). A computer model for the analysis of ground movements in London Clay. Géotechnique 29, No. $2,149-175$.

W. Powrie, Cambridge University Engineering Department

\section{NOTATION}

$A$ parameter defined in the text

$E$ Young's modulus (soil)

$K \sigma_{\mathrm{h}}{ }^{\prime} / \sigma_{\mathrm{v}}{ }^{\prime}$, current lateral earth pressure coefficient

$K_{\mathrm{f}}$ immediately pre-excavation lateral earth pressure coefficient

$K_{0}$ in situ lateral earth pressure coefficient

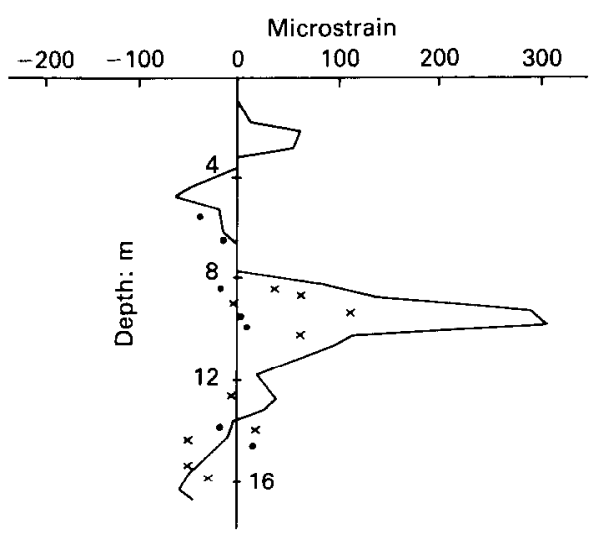

Fig. 12. 
$u$ porewater pressure

$z$ depth below initial ground level

a $\quad E_{\mathrm{v}}{ }^{\prime} / E_{\mathrm{h}}{ }^{\prime}=v_{\mathrm{vh}}{ }^{\prime} / v_{\mathrm{hv}}{ }^{\prime}$, measure of anisotropy

$\gamma$ unit weight of saturated soil

$\gamma_{b}$ unit weight of bentonite slurry or wet concrete (see text)

$\gamma_{w}$ unit weight of water

$\Delta$ prefix denoting incremental change

E. strain

$v_{v h}$ ' Poisson's ratio $=-$ horizontal strain: applied vertical strain

$v_{\text {hv' }}$ Poisson's ratio $=-$ vertical strain:applied horizontal strain

$v_{\mathrm{hh}}$ ' Poisson's ratio $=-$ horizontal strain: applied horizontal strain

$\sigma$ stress

\section{Subscripts and superscripts}

h subscript denoting horizontal direction perpendicular to the wall

I subscript denoting horizontal direction parallel to the wall

u subscript denoting undrained (total stress analysis) parameters

$v$ subscript denoting vertical direction

vol subscript denoting volume

superscript denoting effective stresses and effective stress parameters

It has been assumed that the construction of a diaphragm-type retaining wall will not affect the in situ soil stresses. This is unlikely to be so: the lateral earth pressure in the direction perpendicular to the wall is reduced (or increased) during the slurry trench phase to the hydrostatic pressure of liquid bentonite. Subsequently, as the bentonite slurry is displaced by wet concrete, the total horizontal stress will be increased to some value between the hydrostatic pressure of bentonite slurry (if the concrete sets immediately on pouring) and that of wet concrete (if the concrete does not set until the full depth has been poured). A simple analysis can be used to estimate upper and lower limits to the relevant pre-excavation lateral earth pressure and is summarized here.

It will be assumed that the appropriate mode of deformation is plane strain, so the analysis is less obviously applicable to a secant pile wall than to a diaphragm wall cast in panels that are long enough for three-dimensional effects to be negligible. The soil is modelled as a reversible, linear elastic, cross-anisotropic material. This is somewhat naïve but is reasonable as an approximation as long as the soil deformations are small.

The soil has saturated unit weight $\gamma$. The directions of stresses, strains and elastic

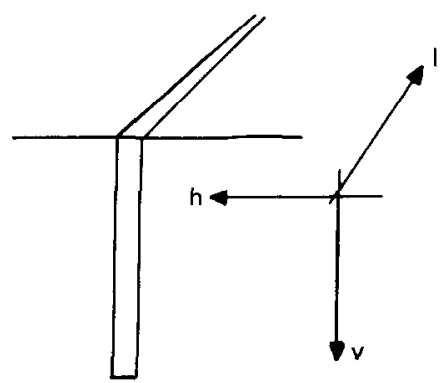

Fig. 13. Directions of stresses, strains and soil parameters

parameters are denoted by subscripts as indicated in Fig. 13. Soil moduli are taken as $E_{\mathrm{v}}{ }^{\prime}=\alpha E_{\mathrm{h}}{ }^{\prime}$ and Poisson's ratios $v_{\mathrm{hh}}{ }^{\prime}$ and $v_{\mathrm{vh}}{ }^{\prime}=\alpha v_{\mathrm{hv}}{ }^{\prime}$. The analysis is performed in terms of effective stresses throughout.

The in situ soil conditions are (at a depth $z$ )

$$
\begin{aligned}
\sigma_{\mathrm{v}} & =\gamma z \\
\sigma_{\mathrm{h}}{ }^{\prime} & =K_{0} \sigma_{\mathrm{v}}{ }^{\prime} \\
\sigma_{1} & =\sigma_{\mathrm{h}} \\
u & =\gamma_{\mathrm{w}} z \text { (groundwater hydrostatic) }
\end{aligned}
$$

During the slurry trench phase of wall construction, the total horizontal stress $\sigma_{\mathrm{h}}$ is reduced (or increased) to a value given approximately by $\gamma_{b} z$ where $\gamma_{b}$ is some value between the unit weight of bentonite slurry and that of wet concrete. The initial soil response is one of undrained shearing, in which excess porewater suctions (or pressures) are generated because, instantaneously at least, the volumetric soil strain is zero. Then

$$
\begin{aligned}
\sigma_{\mathrm{v}} & =\gamma z \\
\sigma_{\mathrm{h}} & =\gamma_{\mathrm{b}} z \\
\Delta \varepsilon_{1} & =0 \quad \text { (plane strain assumption) } \\
\Delta \varepsilon_{\mathrm{vol}} & =0 \\
\Delta \varepsilon_{\mathrm{h}} & =\frac{1}{E_{\mathrm{h}}{ }^{\prime}}\left(\Delta \sigma_{\mathrm{h}}{ }^{\prime}-v_{\mathrm{hb}}{ }^{\prime} \Delta \sigma_{1}^{\prime}-\frac{v_{\mathrm{vh}}{ }^{\prime}}{\alpha} \Delta \sigma_{\mathrm{v}}{ }^{\prime}\right)
\end{aligned}
$$

etc. whence

$$
\begin{aligned}
& \Delta u=\left[\gamma_{\mathrm{b}}-K_{0}\left(\gamma-\gamma_{\mathrm{w}}\right)-\gamma_{\mathrm{w}}\right] \\
& \times\left(1-v_{\mathrm{hv}}{ }^{\prime}-v_{\mathrm{hv}}{ }^{\prime} \nu_{\mathrm{hh}}{ }^{\prime}-v_{\mathrm{hh}}{ }^{2}\right) z \\
& \times\left(1+1 / \alpha-2 v_{\mathrm{hv}}{ }^{\prime}-v_{\mathrm{hv}}{ }^{\prime 2}-2 v_{\mathrm{hh}}{ }^{\prime} v_{\mathrm{hv}}{ }^{\prime}-{v_{\mathrm{hh}}}^{\prime 2}\right)^{-1}
\end{aligned}
$$




$$
\begin{aligned}
& u_{\text {transient }}=\gamma_{\mathrm{w}} z\left\{1+\left[\gamma_{\mathrm{b}} / \gamma_{\mathrm{w}}-K_{0}\left(\gamma / \gamma_{\mathrm{w}}-1\right)-1\right]\right. \\
& \times\left(1-v_{\mathrm{hv}}{ }^{\prime}-v_{\mathrm{hv}}{ }^{\prime} v_{\mathrm{hh}}{ }^{\prime}-v_{\mathrm{hh}}{ }^{\prime 2}\right) \\
& \left.\times\left(1+1 / \alpha-2 v_{\mathrm{hv}}{ }^{\prime}-v_{\mathrm{hv}}{ }^{\prime 2}-2 v_{\mathrm{hh}}{ }^{\prime} v_{\mathrm{hv}}{ }^{\prime}-v_{\mathrm{hh}}{ }^{\prime 2}\right)^{-1}\right\} \\
& =A \gamma_{\mathrm{w}} z
\end{aligned}
$$

which defines $A$. If the soil is isotropic so that $\alpha=1$ and $v_{\mathrm{hv}}{ }^{\prime}=v_{\mathrm{hh}}{ }^{\prime}$, this equation reduces to

$$
u_{\text {transient }}=\gamma_{\mathrm{w}} z\left\{1+0 \cdot 5\left[\frac{\gamma_{\mathrm{b}}}{\gamma_{\mathrm{w}}}-K_{0}\left(\frac{\gamma}{\gamma_{\mathrm{w}}}-1\right)-1\right]\right\}
$$

an expression more simply reached via a total stress analysis using undrained soil parameters $E_{\mathrm{u}}$ and $v_{\mathrm{u}}=0.5$.

It is reasonable to assume that the concrete sets quickly (after which it is capable of sustaining increased lateral pressures), before any significant porewater pressure dissipation has occurred. If $\gamma_{\mathrm{b}}=\gamma$, the soil is now in a state such that $K=\sigma_{\mathrm{h}}{ }^{\prime} / \sigma_{\mathrm{v}}{ }^{\prime}=1$, but the porewater pressures are only transient. None the less, if excavation were also to take place quickly, the pre-excavalion earth pressure coefficient would be unity. Thus $K_{\mathrm{f}}=1$ represents one of the bounds that we seek. Our second limit will be found by allowing the porewater pressures to return to hydrostatic equilibrium before proceeding with the excavation.

With the concrete set and the excavation not yet made, symmetry dictates that $\Delta \varepsilon_{\mathrm{h}}$ is zero or negative: in the latter case, tension cracks open and $\sigma_{\mathrm{h}}$ drops to zero. (Note that it is assumed here that the concrete is very much stiffer than the soil. If this is incorrect, the assumption will simply result in the estimated range for $K_{\mathrm{f}}$ being wider than is the case.) Considering first the case $\Delta \varepsilon_{\mathrm{h}}=0$

$$
\begin{aligned}
\sigma_{\mathrm{vf}} & =\gamma z \\
u_{\mathrm{f}} & =\gamma_{\mathrm{w}} z \\
\Delta \varepsilon_{\mathrm{h}} & =\Delta \varepsilon_{1}=0 \\
\Delta \varepsilon_{\mathrm{h}} & =\frac{1}{E_{\mathrm{h}}{ }^{\prime}}\left(\Delta \sigma_{\mathrm{h}}{ }^{\prime}-v_{\mathrm{hh}}{ }^{\prime} \Delta \sigma_{\mathrm{l}}{ }^{\prime}-\frac{\nu_{\mathrm{vh}}{ }^{\prime}}{\alpha} \Delta \sigma_{\mathrm{v}}{ }^{\prime}\right)
\end{aligned}
$$

etc. whence

$$
\begin{aligned}
\sigma_{\mathrm{vf}}{ }^{\prime} & =\gamma_{\mathrm{w}} z\left(\frac{\gamma}{\gamma_{\mathrm{w}}}-1\right) \\
\sigma_{\mathrm{hf}}{ }^{\prime} & =\gamma_{\mathrm{w}} z\left(\frac{\gamma_{\mathrm{b}}}{\gamma_{\mathrm{w}}}-A-\frac{1-A}{\alpha} \frac{v_{\mathrm{vh}}{ }^{\prime}}{1-v_{\mathrm{hh}}{ }^{\prime}}\right) \\
K_{\mathrm{f}} & =\frac{\sigma_{\mathrm{hf}}{ }^{\prime}}{\sigma_{\mathrm{vf}}{ }^{\prime}}=\left(\frac{\gamma_{\mathrm{b}}}{\gamma_{\mathrm{w}}}-A-\frac{1-A}{\alpha} \frac{v_{\mathrm{vh}}{ }^{\prime}}{1-v_{\mathrm{hh}}{ }^{\prime}}\right) /\left(\frac{\gamma}{\gamma_{\mathrm{w}}}-1\right)
\end{aligned}
$$

For $\gamma=2 \gamma_{\mathrm{w}}, \alpha=1$ (no anisotropy), $v^{\prime}=0 \cdot 2$ and $\gamma_{\mathrm{b}}=\gamma$, this analysis gives the bounds on $K_{\mathrm{f}}$ for $K_{0}=0.5$ and $K_{0}=2.0$ given in Table 1 .

Table 1

\begin{tabular}{l|l|l}
\hline$K_{0}$ & $K_{\mathrm{f} \min }$ & $K_{\mathrm{f} \max }$ \\
\hline 0.5 & 0.63 & 1.0 \\
2.0 & 1.0 & 1.38 \\
\hline
\end{tabular}

It should be noted that $\sigma_{\mathrm{h}}{ }^{\prime}$ and $\sigma_{\mathrm{h}}$ are positive in both cases, verifying the assumption that $\Delta \varepsilon_{\mathrm{h}}=0$ rather than $\Delta \varepsilon_{\mathrm{h}}<0$.

If the soil is twice as stiff horizontally than vertically $(\alpha=0.5), K_{\mathrm{fmax}}=1.22$ for an initial $K_{0}=2 \cdot 0$. Even if it is appropriate to use the full hydrostatic pressure of wet concrete $\left(\gamma_{b}=\right.$ $\left.2 \cdot 3 \gamma_{\mathrm{w}}\right)$, the slurry trench operation will cause an initial $K_{0}$ of 2 to fall to $K_{\mathrm{f} \max }=1.56(1.46$ in the anisotropic case).

Thus the construction process will inevitably have a highly significant effect on the relevant earth pressure coefficient of the soil, but this cannot be appreciated if the transient variations in porewater pressure are neglected.

It would be interesting to see the results of further numerical investigations on in situ walls subjected to variations in the groundwater regime. Initial results from the current programme of model diaphragm wall tests in the Cambridge Geotechnical Centrifuge indicate that an understanding of the groundwater conditions is vital to any prediction of the stability and performance of the wall. 